Revista de

Contabilidade e

Organizações

www.rco.usp.br
DOI: http://dx.doi.org/10.11606/issn.1982-6486.rco.2020.164488
Journal of

Accounting and

Organizations

\title{
Suavização de resultados e comparabilidade dos relatórios financeiros: evidências em empresas abertas do mercado brasileiro
}

\section{Income smoothing and comparability of financial reports: evidence from public companies in the Brazilian market}

\author{
Allison Manoel de Sousa ${ }^{a}$, Alex Mussoi Ribeiro ${ }^{b}, E^{2}$ esto Fernando Rodrigues Vicente ${ }^{\mathrm{b}}$, Carlos Henrique Silva \\ do Carmo $^{\mathrm{c}}$ \\ a Universidade Federal do Paraná \\ ${ }^{b}$ Universidade Federal de Santa Catarina
}

${ }^{c}$ Universidade Federal de Goiás

\section{Palavras-chave}

Comparabilidade.

Qualidade da informação contábil.

Suavização intencional de resultados.
Keywords

Comparability.

Quality of accounting information.

Intentional income smoothing.
Informações do artigo

Recebido: 28 de novembro de 2019

Aprovado: 16 de junho de 2020

Publicado: 29 de junho de 2020

\section{Resumo}

Este estudo objetiva analisar a influência da suavização intencional de resultados na comparabilidade dos relatórios financeiros. A amostra corresponde a 87 companhias, considerando períodos trimestrais de 2013 a 2017. Para o cálculo da medida de comparabilidade, optou-se pelo método da similaridade da função contábil de DeFranco, Kothari e Verdi (2011) e para mensurar a suavização intencional de resultados, utilizou-se duas medidas que capturam diferentes dimensões da suavização, apresentadas no trabalho de Lang, Lins e Maffett, (2012). Os dados foram analisados por meio da regressão quantílica. Os resultados obtidos indicam que a suavização intencional de fato prejudica a comparabilidade. Contudo, quando analisada a suavização intencional de resultados por accruals, houve indícios de reflexo sobre a comparabilidade apenas no quantil que compreende às observações com os menores níveis comparabilidade. Para a maioria das empresas analisadas, a suavização por accruals é menos nociva para a comparabilidade do que a suavização mais geral, que incluí também a suavização operacional. Este aspecto foi observado no trabalho de Sohn (2016) e pode estar relacionado ao problema de o gerenciamento operacional ser mais profundo e persistente do que o gerenciamento por accruals.

\begin{abstract}
The aim of this study is to analyze the influence of the intentional income smoothing on the comparability of financial reports. Our sample is composed by 87 companies, considering quarterly periods from 2013 to 2017. For the measure of comparability, we opted the method of similarity of the accounting function presented by DeFranco, Kothari and Verdi (2011) and for the intentional income smoothing, we used two measures that capture different dimensions of income smoothing presented by Lang, Lins and Maffett, (2012). The data were analyzed using quantile regression. Our results indicate that intentional smoothing in fact impairs comparability. However, when we analyzed the intentional smoothing of results by accruals, we found evidence of a reflex on comparability only in the quantile that comprises the observations with the lowest comparability levels. For most companies analyzed, accrual smoothing is less detrimental to comparability than more general smoothing, which also includes operational smoothing. This aspect was observed by Sohn (2016) and may be related to the problem of operational management being more profound and persistent than management by accruals.
\end{abstract}

\section{Implicações práticas}

A comparabilidade é o cerne do processo decisório para alocação de capital de grande parte dos usuários dos relatórios financeiros. Este estudo aborda um aspecto relevante desta dinâmica, o reflexo da manipulação de resultados sobre o nível de comparabilidade dos relatórios financeiros. Ao suavizar resultados, os gestores procuram demonstrar uma posição atrelada a menores níveis de risco aos investidores e credores. Contudo, este tipo de manipulação prejudica a capacidade de comparar os relatórios e, como consequência, diminui a eficiência informacional para todo o mercado.

Copyright (C) 2020 FEA-RP/USP. Todos os direitos reservados

Autor correspondente: Tel. (67) 981364675

E-mail: allison.msousa@gmail.com (A. M. de Sousa); alex.mussoi@ufsc.br (A. M. Ribeiro); ernesto.vicente@ufsc.br (E. F. R. Vicente); chscarmo@uol.com.br (C. H. S. do Carmo)

Universidade Federal do Paraná. Avenida Prefeito Lothario Meissner, 632 - Jardim Botânico, Curitiba/PR - 80210170, Brasil.

Agradecimento: O presente trabalho foi realizado com apoio da Coordenação de Aperfeiçoamento de Pessoal de Nível Superior - Brasil (CAPES) - Código de Financiamento 001 


\section{INTRODUÇÃ̃O}

Os relatórios financeiros servem como importante meio de comunicação de uma companhia com seus stakeholders. Nestes relatórios, os gestores conseguem mostrar ao mercado um pouco de suas estratégias no ambiente de negócios, os riscos de suas empresas e o retorno que elas podem proporcionar (Healy \& Wahlen, 1999). Entre as informações mais populares que estão presentes nos relatórios financeiros, destaca-se o lucro. Embora o lucro seja criticado no mercado financeiro por conter maior discricionariedade em comparação ao fluxo de caixa, fornece um retrato do desempenho econômico-financeiro da companhia e serve como parâmetro decisório de uma gama relevante de investidores e credores $(\mathrm{Ge}, 2009)$. Esta mesma medida que baliza os usuários externos em suas decisões de investimento, também, serve como métrica de desempenho interno, além de ser utilizada como parâmetro para remunerar os gestores e os demais empregados em uma organização.

Em decorrência da relevância relativa ao lucro, tanto para o usuário externo quanto para o usuário interno, os gestores (responsáveis por fornecer a informação) podem possuir interesse particular em gerenciar esta medida de desempenho com o propósito de suprir seus anseios privados. De acordo com Scott (2015), o gerenciamento de resultados possui uma ampla gama de justificativas e reflexos na qualidade da informação financeira. Segundo os pioneiros no assunto, como Healy (1985) e Jones (1991), a manipulação consciente da informação financeira prejudica a sua qualidade, contribuindo para aumentar a assimetria informacional e os custos de transação para o mercado.

Uma das formas mais populares e estudadas de manipulação de resultados é a suavização dos lucros (Ronen \& Sadan, 1981). Segundo Eckel (1981), existem dois tipos de suavização de resultados. A primeira corresponde à suavização natural, que depende dos próprios fluxos de entrada e saída de recursos em uma entidade. A segunda consiste na suavização intencional, que deriva da ação do gestor na tentativa deliberada de alterar estes fluxos para cumprir um objetivo privado. Gordon (1966) menciona que uma forma de suavizar os resultados consiste em constituir reservas para revertê-las em períodos de queda de lucratividade, deixando de reportar o desempenho fidedigno da empresa. Doupuch e Drake (1966) descrevem que os métodos contábeis com maior discricionariedade apresentam tendência natural de serem manipulados, ou seja, a manipulação para suavizar os resultados é mais factível por meio de accruals.

Como o objetivo da suavização intencional é atingir o objetivo privado do gestor e esconder a performance real da empresa (Gordon, 1966). Este tipo de manipulação tende em contribuir negativamente à qualidade da informação financeira. Sobre isso, Dechow, Ge e Schrand (2010) argumentam que quando há impactos consideráveis nos resultados, a suavização intencional de resultados prejudica a qualidade dos relatórios financeiros. Schipper e Vincent (2003), ao considerarem a persistência dos lucros como um dos aspectos de qualidade dos relatórios financeiros, argumentam que componentes de transitoriedade (como a suavização intencional) diminuem a persistência dos lucros e prejudicam a qualidade dos relatórios financeiros.

Evidências empíricas adicionais apontam que a suavização prejudica, também, outras medidas de qualidade dos relatórios financeiros, como o conservadorismo. Gassen, Fülbier e Sellhorn (2006) apontam que a suavização de resultados pode diminuir a velocidade com que as perdas se refletem nos números contábeis, diminuindo o conservadorismo condicional. No Brasil, Almeida, Sarlo Neto, Bastianello e Moneque (2012) encontraram que empresas "não suavizadoras" possuem maior grau de conservadorismo condicional. Outros trabalhos, também, apresentaram resultados semelhantes em países com diferentes características institucionais (Talebnia \& Javanmard, 2011; Al-Taie, Flayyuh \& Talab, 2017). Ademais, a suavização intencional de resultados, também, é prejudicial à transparência (Lang, Lins \& Maffett, 2012). Assim, a suavização de resultados pode diminuir a qualidade dos relatórios financeiros e, desta forma, afetar os custos de transações nos mercados financeiros, impactando a eficiência na alocação de recursos por parte dos usuários de tais informações.

O processo decisório dos usuários externos é fundamentado em duas decisões principais: alocar o capital, entre as alternativas possíveis de investimentos, e dar continuidade ou não aos investimentos existentes (Healy \& Palepu, 2001). Com respaldo nestas premissas, entende-se a necessidade do investidor em ter acesso ao nível informacional adequado, com informações tempestivas e de qualidade. Com base nas informações financeiras, os seus usuários podem avaliar os riscos e os retornos de um investimento e de outros e, assim, comparar qual é a melhor alternativa dado sua função de risco. 
Neste ambiente decisório, a comparabilidade dos relatórios financeiros se destaca. Segundo o Financial Accouting Standards Board (FASB) (2010), comparabilidade é a capacidade que a informação financeira possui em demonstrar o que é igual ou diferente entre dois indivíduos ou, ainda, do mesmo sujeito ao longo do tempo. Embora não seja considerada como uma característica principal de qualidade no âmbito da regulação contábil (FASB, 2010), a comparabilidade é o alicerce de qualquer processo decisório que envolve diferentes alternativas de investimento e pode afetar diretamente os custos de transação em uma economia de mercado (Kang \& Stluz,1997). Pesquisas relacionadas à comparabilidade, indicam uma série de vantagens relacionadas com a sua presença, tais como: facilidade de alocação de capital entre países (Yip \& Young, 2012; DeFond, Hu, Hung \& Li, 2011; Fang, Maffett \& Zhang, 2015), diminuição do custo da dívida (Kim, Li, Lu \& Yu, 2016) e aumento na qualidade da previsão dos analistas (DeFranco et al., 2011; Reina, Carvalho, Reina \& Lemes, 2019).

Não obstante, alguns trabalhos teóricos e empíricos se atentaram em discutir sobre o efeito da suavização de resultados na qualidade dos relatórios financeiros (Schipper \& Vincent, 2003; Gassen et al. 2006; Tucker \& Zarowin, 2006; Talebnia \& Javanmard, 2011; Kolozsvari \& Macedo, 2016; Al-Taie et al., 2017). Mesmo assim, poucas pesquisas se debruçaram especificamente sobre o impacto do gerenciamento de resultados na comparabilidade. A pesquisa de Sohn (2016), por exemplo, analisou o gerenciamento de resultados reais e por accruals e constatou que eles afetam a comparabilidade. Já Yang, Su, Zhou \& Li (2016), encontraram relação negativa entre o gerenciamento de resultados por accruals e a comparabilidade, em uma perspectiva de republicação dos relatórios financeiros em empresas chinesas. Chen e Gong (2019), por sua vez, elucidaram que a comparabilidade mitiga a importância dos accruals passíveis de serem gerenciados como fator informacional do mercado e a pesquisa de Ahmed, Neel e Safdar (2019) revelou que a anomalia dos accruals é menor em empresas que tem relatórios financeiros mais comparáveis.

Embora estas pesquisas demonstrem um efeito negativo do gerenciamento de resultados na comparabilidade, nenhuma delas testou a suavização como medida de gerenciamento, além de que elas foram conduzidas, em sua maioria, em mercados desenvolvidos. No Brasil destaca-se o estudo de Ribeiro, Carmo, Fávero e Carvalho (2016a), que analisaram a comparabilidade e o poder discricionário do gestor. Os autores concluem que um poder discricionário maior favorece a comparabilidade no sentido de incorporar os diferentes nuances dos modelos de negócios aos números contábeis. Os autores, contudo, não analisaram a discricionariedade negativa da manipulação contábil.

Nesta pesquisa, o objetivo é avançar nesta direção e consiste em analisar a influência da suavização intencional de resultados na comparabilidade dos relatórios financeiros. A suavização de resultados pode ser um assunto controverso quando relacionada com a comparabilidade da informação financeira. Empresas que suavizam mais os resultados podem aumentar a uniformidade de seus relatórios financeiros e, com isso, aumentar a sua comparabilidade - embora sejam constructos diferentes, existe uma parte que a uniformidade e a comparabilidade se permeiam, conforme Ribeiro, Carmo, Fávero e Carvalho (2016b). Estudos como os de Tucker e Zarowin (2006) e Gassen et al. (2006) demonstram que a suavização de resultados pode trazer efeitos positivos para a persistência dos lucros e, por sua vez, para as medidas de conservadorismo condicional entre empresas de diferentes países, o que, de alguma forma, poderia trazer um efeito positivo para comparabilidade. A ideia da comparabilidade "genuína" (Ribeiro, 2014), por outro lado, tenderia a sofrer uma perda com a suavização intencional, pois as empresas apresentariam limitações em transparecer a sua real performance.

As medidas de suavização utilizadas nesta pesquisa foram as mesmas do trabalho de Lang et al. (2012). A primeira medida (SUAV1) é a relação da variação do lucro com a variação do fluxo de caixa operacional. A variação do fluxo de caixa é uma proxy para a variação do fluxo econômico da empresa, quanto menor esta razão maior a suavização de resultados, pois a empresa iria ajustar o lucro para diminuir a volatilidade. A segunda variável utilizada (SUAV2) é a medida de suavização por accruals, ao calcular a correlação dos accruals totais em relação ao fluxo de caixa operacional. Quanto menor for a correlação, maior é a suavização de resultados, sendo que -1 seria suavização máxima.

Cabe destacar, que as medidas finais de suavização foram extraídas dos resíduos de um modelo com a intenção de controlar a suavização natural, ou seja, são medidas que capturam a suavização intencional. As duas medidas de suavização representam diferentes dimensões do gerenciamento. A primeira medida é mais ampla e mede a suavização por accruals, assim como, por aspectos operacionais, pois considera a variação total no lucro. A segunda medida, por sua vez, é mais específica para manipulação por accruals. No estudo feito por Zang (2012), o autor indica que existe um trade-off entre o gerenciamento por accruals e o gerenciamento por operações. Em decorrência disto, optou-se pela utilização de duas medidas para suavização. Os resultados encontrados da fraca correlação entre as medidas nesta pesquisa corroboram com a tese de Zang (2012) de complementariedade das medidas. 
Para medida de comparabilidade foi utilizada a medida desenvolvida por DeFranco et al. (2011) da similaridade da função contábil. Esta medida considera que o preço de uma ação reage de modo mais tempestivo às novas informações do que o lucro contábil. Esta teoria é conhecida como price leads earnings e já foi comprovada empiricamente pelos trabalhos de Beaver, Lambert e Ryan (1987), Beaver, Lambert e Morse (1980) e Brugni, Fávero, Flores e Beiruth (2015). Como o preço incorpora a informação de modo mais tempestivo, ele pode servir de proxy para o conjunto de eventos econômicos de uma determinada empresa em um certo período. O lucro, por sua vez, também incorpora as informações refletidas no preço, mas apenas em uma data específica (publicação do relatório) e depois que a informação foi interpretada, processada e disponibilizada pelos preparadores aos usuários. O modelo de DeFranco et al. (2011) consegue capturar esta dinâmica e utiliza o evento econômico de uma empresa no modelo contábil da outra empresa para calcular a comparabilidade.

Os resultados obtidos, nesta pesquisa, indicam que a suavização intencional geral (SUAV1) prejudica a comparabilidade em todos os quantis analisados. Já a suavização intencional de resultados por accruals (SUAV2), não possui reflexo sobre a comparabilidade, exceto no quantil que compreende às observações com os menores níveis comparabilidade, visto que o seu efeito foi positivo. Este resultado demonstra que a suavização intencional de resultados é prejudicial ao mercado, pois pode aumentar o seu custo de transação e afetar o seu funcionamento de modo eficiente. O fato da variável SUAV2 não ter sido prejudicial, pelo contrário, teve efeito positivo de modo significativo para os menores níveis de comparabilidades, também, reflete a faceta da dinâmica informacional no mercado.

Para a maioria das empresas analisadas, a suavização por accruals é menos nociva para a comparabilidade do que a mais geral, que incluí também a suavização operacional. Este aspecto foi observado no trabalho de Sohn (2016) e pode estar relacionado ao problema de o gerenciamento operacional ser mais profundo e persistente do que o gerenciamento por accruals. É mais difícil para um gestor cuja intenção, por exemplo, seja reduzir seu lucro, diminuir sua receita de vendas (pois, este é um elemento geralmente de baixa transitoriedade) do que aumentar temporariamente sua estimativa de perdas com créditos de liquidação duvidosa. A questão é que com o aumento da vigilância sobre as ações dos gestores por parte dos auditores externos e dos comitês de governança corporativa, os mesmos se sentem inibidos a suavizar os resultados por accruals. Esta redução do espaço para utilizar accruals faz com que os gestores recorram a estratégias operacionais para suavizar os seus resultados, prejudicando, ainda mais, a comparabilidade, devido à maior persistência dos efeitos nocivos do gerenciamento operacional (Zang, 2012).

\section{FUNDAMENTAÇÃO TEÓRICA}

Na visão regulatória da contabilidade, a comparabilidade é uma característica qualitativa que possibilita identificar as semelhanças e diferenças entre pelo menos dois itens (FASB, 2010). Estes dois itens estão relacionados com a referência de comparação e podem ser empresas distintas ou a mesma companhia ao longo do tempo. Relatórios financeiros mais comparáveis são necessários, pois reduzem o custo para obtenção de informações e agilizam o modo como as mesmas são processadas pelos seus usuários (Kang \& Stluz, 1997). Em uma economia de mercado, esta característica pode ser considerada como uma implicação positiva e gera benefícios aos usuários externos, por exemplo, a diminuição dos custos de transação.

Na visão acadêmica, a comparabilidade está ligada à ideia de que o sistema contábil é um mecanismo que mapeia os eventos econômicos (Simmons, 1967; DeFranco et al., 2011). Este sistema de mapeamento envolve as etapas de reconhecimento e mensuração, culminando com a evidenciação dos relatórios financeiros. O produto final do mapeamento é o lucro, que incorpora a visão dos gestores sobre como os eventos econômicos afetaram o patrimônio de uma organização dentro do período avaliado.

Esta visão da comparabilidade foi definida no trabalho de DeFranco et al. (2011), em que é conhecida como similaridade da função contábil. A visão da comparabilidade como uma medida de output (distinta da visão por inputs nos modelos de índices de harmonização) foi bem aceita pela academia e, já é uma métrica amplamente utilizada para medir o fenômeno, tendo em vista a grande quantidade de estudos recentes que a utilizaram (para uma lista completa de tais estudos, ver Ribeiro (2014)).

No que tange aos trabalhos empíricos que utilizaram a medida da comparabilidade de DeFranco et al. (2011), diferentes facetas já foram analisadas. Entre elas estão: a qualidade da previsão dos analistas de mercado (DeFranco et al. 2011), a facilidade de circulação do fluxo de capital entre mercados de diferentes países (DeFond, et al. 2011; Barth, Landsman, Lang \& Williams, 2012; Yip \& Young, 2012; Brochet, Jagolinzer \& Riedl, 2013), o reflexo de diferentes estratégias regulatórias (Ribeiro et al., 2016a) e como a medida é afetada por práticas de gerenciamento de resultados (Sohn, 2016; Yang et al., 2016). 
Dentro do escopo desta pesquisa, os trabalhos que mais se aproximam do racional aqui empregado foram desenvolvidos por Sohn (2016) e por Yang et al. (2016). No artigo de Sohn (2016), o seu objetivo foi testar como a comparabilidade exerce influência nas práticas de gerenciamento por accruals e por operações. O autor encontrou que as empresas mais comparáveis apresentam menor uso de práticas de gerenciamento de resultados utilizando accruals discricionários, mas apresentam maior uso de gerenciamento de resultados por meio de operações. Sohn (2016) afirma que existe uma "fuga" das práticas de gerenciamento por accruals para gerenciamento operacional quando a comparabilidade é maior.

O trabalho de Yang et al. (2016), por sua vez, testou como as práticas de gerenciamento de resultados operacionais e por accruals afetaram a republicação dos relatórios de empresas chinesas e como isto contribui para comparabilidade dos relatórios analisados. Os autores encontraram resultados parecidos com os do estudo de Sohn (2016), pois evidenciaram o antagonismo nas práticas de gerenciamento por accruals e por operações. Yang et al. (2016) destacaram em seus resultados, que as empresas, cujo o nível de gerenciamento por accruals é maior, tendem a republicar mais os seus relatórios, o que não acontece quando o gerenciamento é feito por operações. Os autores ressaltam, também, que a medida de comparabilidade foi impactada positivamente com o ato da republicação, ou seja, a maior transparência das empresas analisadas tendeu a ser revertida em uma maior comparabilidade. Este aspecto foi observado no Brasil na tese de Ribeiro (2014) que testou a adoção das IFRS e o efeito na comparabilidade, ao encontrar efeito positivo da maior transparência sobre a medida.

No que tange ao gerenciamento de resultados por meio da suavização intencional do lucro, destacase que esta forma de manipulação pode ser realizada de duas maneiras: por meio de operações e por meio de accruals. Ambas formas podem ser aplicadas de modo concomitante, embora, sejam antagônicas (Zang, 2012). Este antagonismo entre os métodos de gerenciamento identificado na pesquisa de Zang (2012) faz todo o sentido, pois se a meta da suavização é atingir um objetivo específico (lucro maior ou menor) quando o gestor usa mais de um método deve usar menos de outro. Isto porque o lucro é composto de fluxo de caixa mais accruals.

Já em relação aos trabalhos empíricos, a suavização já foi bastante explorada na década de 80 e 90 (Eckel, 1981; Ronen \& Sadan, 1981; Skinner \& Myers, 1999; Bao \& Bao, 2004), mas ainda existem pesquisas recentes que analisam a medida, por exemplo, Ahmed et al. (2019). As medidas de suavização intencional de resultados ganharam popularidade no começo do século 21. O working paper de Myers e Skinner (1999) - posteriormente publicado como Myers, Myers \& Skinner (2007) - foi um dos pioneiros a criar uma medida de suavização baseada na lógica de accruals definida por Healy (1985). A medida de Myers e Skinner (1999), uma das utilizadas neste trabalho, é calculada por meio da correlação entre accruals totais e o fluxo de caixa operacional. A lógica desta medida é que o fluxo de caixa representa os eventos econômicos que as companhias estão sujeitas e, os accruals são como os gestores interpretam estes eventos. Naturalmente, espera-se coeficiente de correlação negativo entre estas medidas, pois o lucro é composto pelas duas. Se em determinado período uma empresa apresente um lucro $\mathrm{X}$, quanto maior for o caixa operacional, menor serão os itens sujeitos aos accruals.

Essa medida é caracterizada pelas correlações negativas muito acentuadas, onde fica clara a tentativa dos gestores em compensar o movimento do fluxo de caixa. De modo prático, esta compensação pode ser realizada por itens discricionários (como as estimativas com perdas em clientes que podem ser constituídas em um exercício e revertidas em outro), onde o gestor tem espaço para manipulação.

Outra medida de suavização de resultados, utilizada nesta pesquisa, representa uma suavização mais abrangente que é descrita no trabalho de Leuz, Nanda e Wysocki (2003). Tal medida, parte da premissa que apenas as flutuações do resultado poderiam identificar a suavização. Segundo os autores, a menor variação do lucro já seria motivo para suspeita de suavização intencional de resultados. Quanto menor a variação, maior a propensão de que exista práticas de suavização. Embora seja uma lógica interessante, este raciocínio não leva em consideração diferentes setores, bem como, diferentes ciclos de vida de uma companhia, o que poderia influenciar na variação do seu lucro.

Em decorrência desta limitação, Leuz et al. (2003) adaptaram a medida e acrescentaram, também, o desvio-padrão do fluxo de caixa operacional, que neste desenho, faz o papel da volatilidade dos eventos econômicos a que uma empresa está sujeita. A medida utiliza a razão do desvio-padrão do lucro líquido pelo desvio-padrão do fluxo de caixa operacional. Quanto menor for o resultado, maiores são as práticas de suavização. A vantagem desta medida, em relação à medida que captura apenas a variação por accruals, é que ela consegue capturar a suavização mais ampla, onde podem ser empregadas práticas operacionais - tais como, queimar estoque para aumentar a receita - para gerenciar os resultados. Cabe destacar que as duas formas de gerenciamento de resultados, empregadas neste trabalho, são complementares, pois, de acordo com Zang (2012), existe um trade-off entre gerenciamento operacional e por accruals. 
Considerando que muitos trabalhos empíricos encontraram uma relação negativa entre a qualidade do lucro e as práticas de suavização de resultados (Kolosvari \& Macedo, 2016; Schipper \& Vincent, 2003), esta pesquisa teceu a seguinte hipótese direcionadora:

$\mathbf{H}_{1}$ : Existe uma relação negativa entre a suavização intencional de resultados e a comparabilidade dos relatórios financeiros.

\section{TRAJETÓRIA METODOLÓGICA}

A população desta pesquisa corresponde a todas as companhias brasileiras de capital aberto da Brasil Bolsa Balcão (B3). A amostra inicial foi composta pelas empresas que tinham informações disponíveis sobre o retorno de suas ações (necessária para calcular a comparabilidade) entre 2010 e 2017. Com isso, a amostra inicial foi composta por 157 companhias. Posteriormente, estas empresas foram discriminadas conforme o seu setor de atividades econômicas, a partir da classificação setorial North American Classification System (NAICS). Esta classificação foi utilizada, pois é a mais popular nos trabalhos sobre comparabilidade (Lang, Maffett \& Owens, 2010, DeFranco et al., 2011, Yip \& Young, 2012, Ribeiro et al., 2016a, Ribeiro et al., 2016b). A partir desta seleção, foram identificados 31 setores.

Destes setores, escolheu-se os que eram compostos por, pelo menos, quatro empresas. Isso foi necessário, pois, de acordo com Ribeiro (2014), o setor deve ser um controle nos modelos multivariados da comparabilidade. $\mathrm{O}$ autor menciona que é necessário número mínimo de empresas por setor, dado que uma análise com setores que tem poucas companhias carrega os graus de liberdade e, por sua vez, não traz variabilidade adequada para mensurar a medida de comparabilidade. Dada esta restrição, foram selecionados os setores que foram compostos por quatro ou mais empresas, em que, verificou-se que dos 31 setores, apenas 13 poderiam ser objetos de análise na presente pesquisa. Com isso, a amostra ficou composta por, somente, empresas destes 13 setores, os quais tinham em sua totalidade 87 companhias.

Os dados foram coletados ao considerar os períodos trimestrais de 2010 a 2017, pois compreende ao período após a adoção do padrão IFRS no Brasil. Cabe ressaltar que o período inicial de análise corresponde ao primeiro trimestre de 2013, porque para mensurar a medida de comparabilidade e as medidas de suavização intencional de resultados, foi necessário utilizar dados que se referem ao trimestre atual e aos 11 trimestres anteriores de cada empresa. Além disso, destaca-se que todas estas informações foram obtidas por meio da base de dados Economatica ${ }^{\circledR}$. Para manter as características que se referem às operações das empresas analisadas, especialmente, ao considerar a comparabilidade dos relatórios financeiros da mesma forma que adotado nos trabalhos de Ribeiro et al. (2016a), Ribeiro et al. (2016b), Ribeiro, Sousa e Vicente (2019), os dados econômicofinanceiros desta pesquisa são oriundos das demonstrações contábeis não consolidadas.

Quanto aos modelos de base do estudo, destaca-se que para o cálculo da comparabilidade dos relatórios financeiros, recorreu-se à similaridade da função contábil, desenvolvida por DeFranco et al. (2011) (os procedimentos utilizados para o cálculo da medida de comparabilidade constam no Apêndice B). Para mensurar as medidas que compreendem à suavização intencional de resultados, utilizou-se a técnica similar ao trabalho de Lang et al. (2012), (os procedimentos utilizados para o cálculo das medidas de income smoothing constam no Apêndice A).

A variável dependente consiste na comparabilidade dos relatórios financeiros (COMPM) e as variáveis de interesse que correspondem às medidas de suavização intencional de resultados são a SUAV1 e SUAV2. Estas duas variáveis são complementares, ao considerar a lógica apresentada no trabalho de Lang et al. (2012) e na pesquisa de Zang (2012). Na Tabela 1 constam as variáveis dependentes e independentes do modelo multivariado. 
Tabela 1. Variáveis dependente e independentes utilizadas no modelo)

\begin{tabular}{|c|c|c|c|}
\hline Variável & Descrição & Operacionalização & Referências \\
\hline \multicolumn{4}{|c|}{ Variável dependente } \\
\hline $\begin{array}{l}\text { Comparabilidade } \\
\text { (COMPM) }\end{array}$ & $\begin{array}{l}\text { Comparabilidade individual média por } \\
\text { setor }\end{array}$ & $\mathrm{ROA}_{\mathrm{it}}=\alpha_{\mathrm{i}}+\beta_{\mathrm{i}}$ Retorno $_{\mathrm{it}}+\varepsilon_{\mathrm{it}}$ & DeFranco et al. (2011) \\
\hline \multicolumn{4}{|c|}{ Variáveis independentes } \\
\hline SUAV1 & $\begin{array}{l}\text { Suavização intencional geral de } \\
\text { resultados }\end{array}$ & $\begin{array}{c}\text { SMTH1 }_{\text {itt }}=\alpha_{\text {ti }}+\beta_{1} \text { TAM }_{\text {it }}+\beta_{2} \text { DIVIDA }_{\text {it }}+\beta_{3} \text { MB }_{\text {it }}+\beta_{4} \text { DPRECEITA }_{\text {it }}+ \\
\beta_{5} \% \text { PREJUIZO }_{i t}+\beta_{6} \text { CICLO }_{\text {it }}+\beta_{7} \text { CRESCREC }_{i t}+\beta_{8} \text { IMOB }_{\text {it }}+\beta_{9} \text { FLUXO }_{\text {it }}+ \\
\beta_{10} \text { ANO }_{\text {it }}+\beta_{11} \text { SETOR }_{\text {it }}+\varepsilon_{i t}\end{array}$ & Lang et al. (2012) \\
\hline SUAV2 & $\begin{array}{l}\text { Suavização intencional de resultados por } \\
\text { accruals }\end{array}$ & 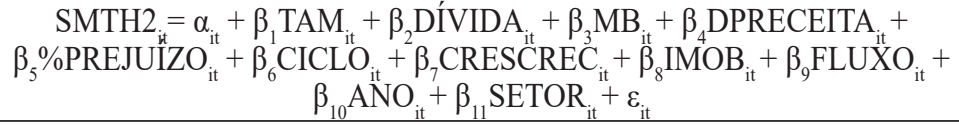 & Lang et al. (2012) \\
\hline \multicolumn{4}{|c|}{ Variáveis de controle } \\
\hline $\begin{array}{l}\text { Grau de alavancagem } \\
\text { operacional (GAO) }\end{array}$ & $\begin{array}{l}\text { Medida que representa uma medida de } \\
\text { desempenho operacional da estrutura de } \\
\text { custos da companhia }\end{array}$ & $\begin{array}{c}\text { Lucro Bruto / (Lucro Bruto - Despesas com Vendas e Despesa } \\
\text { Administrativas) }\end{array}$ & $\begin{array}{l}\text { Sohn (2016); Francis, Hanna e } \\
\text { Vincent (1996); Ribeiro et al. } \\
\text { (2016a) e Ribeiro et al. (2016b) }\end{array}$ \\
\hline Market-to-book(MB) & $\begin{array}{l}\text { Variável que mede a expectativa de } \\
\text { crescimento do negócio para o mercado }\end{array}$ & Valor de Mercado / PL Contábil & $\begin{array}{l}\text { Lee, Li e Yue (2006); Mcvay, } \\
\text { Nagar e Tang (2006); Ribeiro } \\
\text { et al. (2016a); Ribeiro et al. } \\
\text { (2016b) }\end{array}$ \\
\hline Tamanho (TAM) & $\begin{array}{l}\text { Ativo Total de cada companhia } \\
\text { transformado para sua base logarítmica }\end{array}$ & Logaritmo neperiano do Ativo Total & $\begin{array}{l}\text { Watts e Zimmerman (1986); } \\
\text { Doyle, Ge e McVay. (2007); } \\
\text { Ribeiro et al. (2016a); Ribeiro et } \\
\text { al. (2016b) }\end{array}$ \\
\hline SETOR & $\begin{array}{l}\text { Variável do setor de cada companhia } \\
\text { com base na classificação NAICS nível } 2\end{array}$ & $\begin{array}{l}\text { Variável dummy que representa os setores de atividade econômica de } \\
\text { cada companhia: (0) Atividades auxiliares ao transporte, (1) Construção } \\
\text { de edifícios, (2) Empresa de eletricidade, gás e água, (3) Imobiliária, (4) } \\
\text { Indústria de alimentos, (5) Indústria de equipamentos de transporte, (6) } \\
\text { Indústria de fios e tecidos, (7) Indústria de papel, (8) Indústria de produtos } \\
\text { de metal, (9) Indústria de roupas, (10) Indústria química, (11) Outras } \\
\text { indústrias, (12) Siderurgia e indústria básica de outros metais. }\end{array}$ & $\begin{array}{l}\text { Verrecchia e Weber (2006); } \\
\text { Bagnoli e Watts (2010); Ribeiro } \\
\text { (2014); Ribeiro et al. (2016a) } \\
\text { Ribeiro et al. (2016b) }\end{array}$ \\
\hline ANO & Variável que confere aos períodos anuais & Variável dummy que representa os períodos anuais de 2013 a 2017 & $\begin{array}{l}\text { Verrecchia e Weber (2006); } \\
\text { Bagnoli e Watts (2010); Ribeiro } \\
\quad \text { et al. (2019a) }\end{array}$ \\
\hline
\end{tabular}


Além da variável dependente e das variáveis de interesse, a análise multivariada foi composta por variáveis de controle (grau de alavancagem operacional, market-to-book e tamanho) ao considerar a relação com a comparabilidade que constam nas investigações de Ribeiro et al. (2016a) e Ribeiro et al. (2019). Além disso, realizou-se o controle por setores e por períodos anuais, uma vez que cada setor tem suas especificidades quanto às atividades operacionais realizadas, assim como, as características internas e externas das empresas não são semelhantes em todos os períodos, uma vez que se tem mudanças ao longo do tempo.

Para a análise dos dados, recorreu-se à regressão quantílica, com 20 replicações por meio do STATA ${ }^{\circledR}$ 13, uma vez que a influência das duas medidas de suavização intencional de resultados pode ser distinta ao longo da distribuição da comparabilidade. Adicionalmente, o impacto destas duas estratégias de manipulação dos resultados pode ser mais significativo conforme o nível de comparabilidade da companhia. A regressão quantílica foi calculada por meio de cinco quantis, ou seja, 0,$10 ; 0,25 ; 0,50 ; 0,75$ e 0,90 . Vale lembrar que, conforme Greene (2000), a regressão quantílica, por ser fundamentada no método de Minimização dos Erros Absolutos (MEA) e não apresenta os mesmos pressupostos da regressão linear múltipla.

Deste modo, o autor comenta que os testes de normalidade dos resíduos, multicolinearidade, autocorrelação serial e heterocedasticidade não são necessários quando se realiza a análise multivariada por meio da regressão quantílica. Ademais, esta técnica pode auxiliar em investigações que tratam sobre a qualidade da informação contábil, pois se pode analisar o comportamento das observações nos quantis extremos (Duarte, Girão \& Paulo, 2017). Além disso, Duarte et al. (2017) destacam que a regressão quantílica, por não ser fundamentada na média, não tem a necessidade de excluir os outliers, como em modelos fundamentados na média. Neste sentido, o número total de observações foi de 1.740, das quais, 193 compreendem a observações com informações insuficientes, o que resultou em uma amostra final com 1.547 observações.

\section{APRESENTAÇÃO E ANÁLISE DOS RESULTADOS}

$\mathrm{Na}$ Tabela 2, apresenta-se as informações referentes à análise descritiva de todas as variáveis quantitativas que constam no modelo multivariado ao considerar cada período anual.

Os resultados da estatística descritiva revelam que a mediana da comparabilidade, no Painel A, foi de -2,542. Este achado pode ser considerado convergente com os estudos de De Franco et al. (2011), Sohn (2016), Fang et al. (2015) Ribeiro et al. (2016a) e Ribeiro et al. (2019), pois apresentaram média do nível de comparabilidade entre -1,90 e -2,70. Contudo, as medidas que representam a suavização intencional geral e a suavização intencional de resultados por accruals (SUAV1 e SUAV2) tiveram mediana de 0,779 e 0,226, respectivamente. Evidências que não podem ser comparadas com as medidas originais de Lang et al. (2012), já que os autores realizaram a junção destas medidas. As bases para o cálculo da SUAV1 e SUAV2 foram o SMTH1 e SMTH2 (não apresentados), as quais apresentaram mediana de $-0,659$ e $-0,275$, respectivamente. O resultado da SMTH1 é similar ao do trabalho de Lang et al. (2012), porém o valor da mediana da SMTH2 destoa com o apresentado.

A partir disso, pode-se entender que as empresas brasileiras têm nível semelhante de suavização geral de resultados das companhias dos principais mercados acionários do mundo, como analisado por Lang et al. (2012). Entretanto, o nível de suavização por accruals é inferior ao realizado em outros países e, desta forma, nas empresas brasileiras de capital aberto esta estratégia de manipulação pode ser menos nociva à qualidade dos relatórios financeiros. Vale ressaltar, que estas inferências correspondem ao nível de suavização geral de resultados e suavização de resultados por accruals que não tem a distinção da parcela natural e intencional.

Em uma ótica complementar, ao analisar os resultados descritivos dos períodos anuais apresentados no Painel B, observa-se queda no nível de comparabilidade em todos os percentis ao considerar o ano de 2017 e 2013. A diminuição do nível de comparabilidade em termos percentuais no P10, P25, P50, P75 e P90 foi de 44,4\%; 75,9\%; $89,7 \% ; 43,7 \%$, e; 32,8\%, respectivamente. Evidência que está de acordo com o descrito por Ribeiro et al. (2019), haja vista que houve diminuição da comparabilidade ao considerar o período pós implementação da IFRS. Esta evidência pode complementar os achados de Ribeiro et al. (2019), pois o nível de comparabilidade teve acentuada diminuição desde as companhias com os menores até as empresas com os maiores níveis de comparabilidade. 
Tabela 2. Estatística descritiva

\begin{tabular}{lccccccccc}
\hline \multicolumn{7}{l}{ Painel A: estatística descritiva } \\
\hline Variáveis & P10 & P25 & P50 & P75 & P90 & DP & Mín. & Máx. & Obs \\
\hline COMP & $-6,457$ & $-4,411$ & $-2,542$ & $-1,641$ & $-1,135$ & 2,642 & $-20,705$ & $-0,387$ & 1547 \\
SUAV1 & 0,156 & 0,381 & 0,779 & 1,443 & 2,411 & 2,160 & 0,001 & 22,886 & 1547 \\
SUAV2 & 0,041 & 0,108 & 0,226 & 0,385 & 0,558 & 0,194 & 0,001 & 0,967 & 1547 \\
GAO & $-1,823$ & $-0,034$ & 1,485 & 2,499 & 4,315 & 18,641 & $-341,929$ & 346,410 & 1547 \\
MB & 0,233 & 0,535 & 0,944 & 1,596 & 2,370 & 1,341 & $-14,960$ & 23,657 & 1547 \\
TAM & 12,840 & 13,767 & 15,013 & 15,866 & 17,102 & 1,567 & 9,693 & 17,995 & 1547 \\
\hline
\end{tabular}

Painel B: estatística descritiva em cada período anual

\begin{tabular}{|c|c|c|c|c|c|c|c|c|c|}
\hline \multicolumn{10}{|c|}{ Ano de 2013} \\
\hline Variáveis & P10 & $\mathbf{P 2 5}$ & P50 & P75 & P90 & DP & Mín. & Máx. & Obs \\
\hline COMP & $-5,118$ & $-3,311$ & $-2,016$ & $-1,405$ & $-1,089$ & 1,751 & $-8,983$ & $-0,668$ & 324 \\
\hline SUAV1 & 0,126 & 0,316 & 0,674 & 1,064 & 2,059 & 1,609 & 0,004 & 20,584 & 324 \\
\hline SUAV2 & 0,054 & 0,139 & 0,247 & 0,427 & 0,644 & 0,223 & 0,001 & 0,967 & 324 \\
\hline GAO & $-1,458$ & 0,172 & 1,699 & 2,698 & 4,328 & 14,400 & $-99,107$ & 178,368 & 324 \\
\hline $\mathrm{MB}$ & 0,443 & 0,823 & 1,317 & 2,242 & 3,926 & 2,340 & $-14,968$ & 23,657 & 324 \\
\hline TAM & 12,706 & 13,745 & 14,892 & 15,749 & 16,671 & 1,551 & 10,801 & 17,701 & 324 \\
\hline \multicolumn{10}{|c|}{ Ano de 2014} \\
\hline COMP & $-5,648$ & $-3,580$ & $-2,103$ & $-1,467$ & $-1,036$ & 2,017 & $-14,737$ & $-0,387$ & 320 \\
\hline SUAV1 & 0,132 & 0,329 & 0,682 & 1,325 & 2,160 & 1,289 & 0,003 & 8,711 & 320 \\
\hline SUAV2 & 0,042 & 0,105 & 0,243 & 0,423 & 0,557 & 1,998 & 0,001 & 0,863 & 320 \\
\hline GAO & $-2,019$ & $-0,173$ & 1,481 & 2,462 & 4,304 & 27,459 & $-341,929$ & 31,768 & 320 \\
\hline $\mathrm{MB}$ & 0,233 & 0,542 & 0,968 & 1,552 & 2,072 & 0,697 & 0,037 & 3,718 & 320 \\
\hline TAM & 12,840 & 13,728 & 14,966 & 15,734 & 16,952 & 1,534 & 10,973 & 17,769 & 320 \\
\hline \multicolumn{10}{|c|}{ Ano de 2015} \\
\hline COMP & $-6,528$ & $-4,172$ & $-2,513$ & $-1,823$ & $-0,966$ & 2,596 & $-19,379$ & $-0,501$ & 306 \\
\hline SUAV1 & 0,148 & 0,309 & 0,621 & 1,356 & 2,357 & 1,507 & 0,003 & 14,230 & 306 \\
\hline SUAV2 & 0,034 & 0,089 & 0,197 & 0,378 & 0,506 & 0,187 & 0,001 & 0,842 & 306 \\
\hline $\mathrm{GAO}$ & $-1,751$ & $-0,087$ & 1,363 & 2,468 & 4,289 & 5,487 & $-25,038$ & 46,245 & 306 \\
\hline $\mathrm{MB}$ & 0,174 & 0,402 & 0,723 & 1,332 & 2,111 & 0,968 & 0,013 & 6,114 & 306 \\
\hline TAM & 12,957 & 13,858 & 15,132 & 15,848 & 17,135 & 1,558 & 10,342 & 17,999 & 306 \\
\hline \multicolumn{10}{|c|}{ Ano de 2016} \\
\hline COMP & $-7,074$ & $-5,230$ & $-3,029$ & $-2,230$ & $-1,450$ & 2,862 & $-18,573$ & $-0,741$ & 294 \\
\hline SUAV1 & 0,117 & 0,483 & 0,938 & 1,554 & 2,943 & 2,604 & 0,001 & 20,872 & 294 \\
\hline SUAV2 & 0,039 & 0,102 & 0,196 & 0,306 & 0,450 & 0,159 & 0,004 & 0,776 & 294 \\
\hline GAO & $-1,898$ & $-0,156$ & 1,323 & 2,078 & 4,355 & 6,159 & $-49,015$ & 26,630 & 294 \\
\hline $\mathrm{MB}$ & 0,196 & 0,449 & 0,742 & 1,289 & 2,191 & 0,843 & 0,017 & 5,145 & 294 \\
\hline TAM & 12,981 & 13,896 & 15,071 & 15,895 & 17,142 & 1,542 & 10,185 & 17,917 & 294 \\
\hline \multicolumn{10}{|c|}{ Ano de 2017} \\
\hline COMP & $-7,391$ & $-5,826$ & $-3,824$ & $-2,020$ & $-1,446$ & 3,301 & $-20,705$ & $-0,658$ & 303 \\
\hline SUAV1 & 0,259 & 0,593 & 1,047 & 1,895 & 2,830 & 3,179 & 0,002 & 22,885 & 303 \\
\hline SUAV2 & 0,040 & 0,116 & 0,237 & 0,407 & 0,544 & 0,186 & 0,001 & 0,764 & 303 \\
\hline GAO & $-1,424$ & 0,145 & 1,530 & 2,591 & 4,315 & 25,038 & $-135,650$ & 346,418 & 303 \\
\hline $\mathrm{MB}$ & 0,285 & 0,586 & 0,989 & 1,461 & 2,001 & 0,810 & 0,026 & 6,649 & 303 \\
\hline TAM & 12,906 & 13,754 & 15,044 & 16,139 & 17,175 & 1,639 & 9,693 & 17,823 & 303 \\
\hline
\end{tabular}

Fonte: dados da pesquisa.

Legenda: P10 = Percentil 10; P25 = Percentil 25; P50 = Percentil 50; P75 = Percentil 75; P90 = Percentil 90; DP = desvio padrão; Mín. = Mínimo; Máx. = Máximo, e; Obs = Observações. 
Quanto à variação da suavização intencional geral de resultados, nota-se que ao longo dos períodos de análise houve aumento do uso desta estratégia de manipulação de resultados. Isso, porque em quase todos os períodos - exceto no P25 e P50 em 2015, P10 em 2016 e P90 em 2017 - ocorreu aumento na suavização intencional geral de resultados em termos percentuais. Entretanto ao analisar a SUAV2, verifica-se redução no uso de accruals para suavizar resultados pelos gestores em todos os percentis ao longo de todo o intervalo analisado.

Este aspecto nos resultados descritivos corrobora com a tese levantada por Zang (2012) de que as medidas de gerenciamento por accruals e por operações são antagônicas. Tal comportamento pode demonstrar que mecanismos de governança, como os comitês de auditoria estatutários (implementados em período mais recente) e os auditores independentes, estão inibindo práticas de gerenciamento por accruals (Gaganis, Hasan \& Pasiouras, 2016), obrigando os gestores que querem manipular resultados pela suavização recorrer a práticas ligadas às questões operacionais.

Em momento posterior à análise descritiva dos dados, realizou-se o teste de correlação de Pearson, mesmo que não seja um pressuposto necessário para regressão quantílica, como mencionado por Greene (2000). Um ponto central para a realização desta análise compreende ao fato de que a SUAV1 e SUAV2 podem apresentar multicolinearidade, haja vista que captam estratégias de manipulação que são complementares entre si. $\mathrm{O}$ coeficiente de correlação entre a SUAV1 e SUAV2 foi de -0,0236, o que demonstra a complementariedade das medidas. Ademais, os resultados da análise de correlação sugerem que não há multicolinearidade entre as variáveis independentes, pois apresentaram coeficientes de correlação muito inferiores a 0,70, como sugerido por Fávero e Belfiore (2017). Nesse contexto, o próximo passo consistiu em realizar a análise multivariada em quantis para a medida de comparabilidade. Na Tabela 3 são apresentados os resultados dos fatores relacionados à medida de comparabilidade.

Os achados da Tabela 3 demonstram que a SUAV1 está negativamente relacionada com a comparabilidade para todos os quantis analisados. Já a SUAV2 (suavização intencional de resultados por accruals) apresentou resultado não significativo para maioria dos quantis analisados e resultado positivo e significativo para o quantil das empresas com menores níveis de comparabilidade, ou seja, quantil 0,10.

Este resultado indica que, no geral, a suavização intencional de resultados prejudica a comparabilidade dos relatórios financeiros, corroborando a hipótese $\mathrm{H} 1$ testada nesta pesquisa, e com os trabalhos que apontam uma queda na qualidade da informação com o aumento das práticas de suavização intencionais de resultados (Schipper \& Vincent, 2003; Lang et al., 2012; Kolozsvari \& Macedo, 2016).

O fato de a SUAV2 não ter apresentado relação significativa em todos os quantis com a comparabilidade, exceto no quantil 0,10 que corresponde às observações das empresas com os menores níveis de comparabilidade, pode ser explicado a partir de duas lógicas. A primeira envolve o trade-off das medidas de gerenciamento operacional e por accruals como encontrado em Zang (2012). Como as empresas utilizaram mais aspectos ligados a questões operacionais para suavizar resultados (como foi visto no comportamento da SUAV1), naturalmente utilizaram menos accruals e, como foi defendido por Zang (2012), as práticas de gerenciamento por operações são mais nocivas à qualidade da informação do que as práticas de manipulação fundamentadas nos accruals que são mais facilmente revertidas.

A segunda justificativa, envolve o fato de o ganho de uniformidade ser atrelado às práticas de suavização de resultados por accruals. Segundo Tucker e Zarowin (2006), as práticas de suavização de resultados podem aumentar a persistência dos lucros, porque mitigam os desvios do lucro e criam um fluxo de informação mais constante. DeFranco et al. (2011) apontam que existe uma relação positiva entre comparabilidade e persistência. A uniformidade e a comparabilidade são medidas distintas, embora tenham uma convergência inicial, e para se chegar na comparabilidade é necessário se ter o mínimo de uniformidade nas práticas contábeis (Ribeiro et al., 2016b).

As companhias menos comparáveis, ao utilizarem práticas de suavização intencional de resultados por accruals acabam uniformizando os seus resultados, o que, para as empesas menos comparáveis, pode ter trazido um ganho para a medida. Isto ficou claro, pois nos demais quantis não foi observado tal efeito. Como a comparabilidade genuína é diferente da uniformidade (Ribeiro et al., 2016b), o ganho ficou restrito à contribuição mínima da uniformidade que ocorreu apenas para as companhias que apresentaram as piores medidas. 
Tabela 3. Análise multivariada da comparabilidade

\begin{tabular}{|c|c|c|c|c|c|c|c|c|c|c|}
\hline \multicolumn{11}{|c|}{ Comparabilidade } \\
\hline \multirow{3}{*}{ Variáveis } & \multicolumn{10}{|c|}{ Quantil } \\
\hline & \multicolumn{2}{|c|}{0,10} & \multicolumn{2}{|c|}{0,25} & \multicolumn{2}{|c|}{0,50} & \multicolumn{2}{|c|}{0,75} & \multicolumn{2}{|c|}{0,90} \\
\hline & Coef. & Est T & Coef. & Est T & Coef. & Est T & Coef. & Est T & Coef. & Est T \\
\hline SUAV1 & $-0,676$ & $-13,44 * * *$ & $-0,609$ & $-26,06^{* * *}$ & $-0,332$ & $-7,23 * * *$ & $-0,162$ & $-4,74 * * *$ & $-0,137$ & $-4,95 * * *$ \\
\hline SUAV2 & 1,016 & $3,73 * * *$ & 0,113 & 0,70 & $-0,139$ & $-0,93$ & $-0,052$ & $-0,52$ & $-0,006$ & $-0,06$ \\
\hline GAO & $-0,001$ & $-0,40$ & $-0,002$ & $-0,66$ & 0,001 & 0,27 & $-0,001$ & $-0,05$ & $-0,001$ & $-1,36$ \\
\hline MB & $-0,054$ & $-1,20$ & $-0,04$ & $-0,07$ & 0,001 & 0,03 & $-0,040$ & $-0,13$ & $-0,017$ & $-0,68$ \\
\hline TAM & 0,546 & $5,93 * * *$ & 0,314 & $6,57 * * *$ & 0,136 & $4,07 * * *$ & 0,069 & $3,50 * * *$ & 0,044 & $3,58 * * *$ \\
\hline Const. & $-13,157$ & $-8,82 * * *$ & $-8,468$ & $-9,03 * * *$ & $-5,297$ & $-12,42 * * *$ & $-3,794$ & $-13,61 * * *$ & $-3,089$ & $-13,96 * * *$ \\
\hline $\mathrm{CS}$ & \multicolumn{2}{|c|}{ Sim } & \multicolumn{2}{|c|}{ Sim } & \multicolumn{2}{|c|}{$\operatorname{Sim}$} & \multicolumn{2}{|c|}{ Sim } & \multicolumn{2}{|c|}{ Sim } \\
\hline CPA & \multicolumn{2}{|c|}{ Sim } & \multicolumn{2}{|c|}{ Sim } & \multicolumn{2}{|c|}{ Sim } & \multicolumn{2}{|c|}{ Sim } & \multicolumn{2}{|c|}{ Sim } \\
\hline $\mathrm{R}^{2}$ & \multicolumn{2}{|c|}{0,4799} & \multicolumn{2}{|c|}{0,4577} & \multicolumn{2}{|c|}{0,4181} & \multicolumn{2}{|c|}{0,3806} & \multicolumn{2}{|c|}{0,3731} \\
\hline Obs. & \multicolumn{10}{|c|}{1.547} \\
\hline
\end{tabular}

Fonte: dados da pesquisa.

Nota: Const. $=$ Constante; $\mathrm{CS}=$ Controle de Setores; $\mathrm{CP}=$ Controle de Períodos Anuais; Obs = Observações. * significância ao nível de 10\%; **significância ao nível de 5\%; ***significância ao nível de 1\%. As regressões acima foram estimadas por meio do método não paramétrico em quantis $(0,10 ; 0,25 ; 0,50 ; 0,75 \mathrm{e} 0,90)$.

As constantes destes modelos econométricos absorveram as seguintes variáveis: SETOR = Atividades auxiliares ao transporte e ANO = 2013. Os modelos foram obtidos fundamentados a partir das seguintes equações:

COMPM $_{\mathrm{it}}=\beta_{0}+\beta_{1} \mathrm{SUAV}_{1 \mathrm{it}}+\beta_{2} \mathrm{SUAV}_{\mathrm{it}}+\beta_{3} \mathrm{GAO}_{\mathrm{it}}+\beta_{4} \mathrm{MB}_{\mathrm{it}}+\beta_{5} \mathrm{TAM}_{\mathrm{it}}+\beta_{6} \mathrm{CONSTRUÇÃO}_{\mathrm{it}}+\beta_{7}$ ELETRICIDADE $_{\mathrm{it}}+\beta_{8}$ IMOBILIÁRIA $_{\mathrm{it}}+\beta_{9}$ INDALIMENTOS $_{\mathrm{it}}+\beta_{10}$ INDTRANSPORTE $_{\mathrm{it}}+\beta_{11}$ INDTECIDOS $_{\mathrm{it}}$ $\beta_{12}$ INDPAPEL $_{\text {it }}+\beta_{13}$ INDMETAL $_{\text {it }}+\beta_{14}$ INDROUPAS $_{\text {it }}+\beta_{15}$ INDQUIMICA $_{\text {it }}+\beta_{16}$ OUTRASIND $_{\text {it }}+\beta_{17}$ SIDERURGIA $_{\text {it }}+\beta_{18} 2014+\beta_{19} 2015+\beta_{20} 2016+\beta_{21} 2017+\varepsilon_{i t}$ 
Vale ressaltar que existem diferenças nos resultados correspondentes à estatística T e R2 entre os quantis analisados. Estas diferenças evidenciam o impacto em níveis diferentes da suavização intencional na comparabilidade. Entendimento que pode ser justificado ao analisar a estatística $\mathrm{T}$ dos cinco percentis avaliados. O maior nível de significância das observações alocadas no Modelo 1 e no Modelo 2, do que nas observações alocadas no Modelo 4 e no Modelo 5, traz um indício de que as práticas de suavização são mais nocivas aos níveis de comparabilidades das companhias que apresentam os menores níveis desta característica. Este resultado está alinhado com o estudo de Sohn (2016).

\section{CONSIDERAÇÕES FINAIS}

Este estudo teve como propósito analisar a influência da suavização intencional de resultados na comparabilidade dos relatórios financeiros. Os resultados revelaram que a suavização intencional geral de resultados exerce influência negativa na comparabilidade, desde as empresas com os menores até as companhias com os maiores níveis comparabilidade. Este resultado gera contribuições às discussões sobre o tema e corrobora com os achados dos trabalhos de Schipper e Vincent (2003), Lang et al. (2012) e Kolozsvari e Macedo (2016) que encontraram efeito negativo da suavização de resultados sobre a qualidade dos relatórios financeiros. Do ponto de vista prático, suavizar resultados de modo intencional por meio de operações, pode prejudicar a comparabilidade dos relatórios financeiros, comprometendo o poder analítico dos investidores, juntamente com os credores, e contribuindo de modo negativo para o funcionamento eficiente do mercado.

Outra evidência que merece destaque é a diminuição mais acentuada da comparabilidade quando os gestores realizam suavização geral de resultados em empresas que já possuem os menores níveis de comparabilidade. Este reflexo mais nocivo da suavização de resultados em empresas cuja comparabilidade é menor serve como alerta para o mercado das práticas oportunistas dos gestores nos relatórios financeiros. Na perspectiva teórica, essa evidência vai ao encontro dos resultados obtidos por Sohn (2016).

Para finalizar, os resultados demonstram o lado mais perverso da suavização de resultados realizada por meio de operações e comprova a tese de Zang (2012). Existe um trade-off entre o gerenciamento por accruals e por operações. Como possível explicação para este fenômeno, ressaltamos o aprimoramento das práticas de controle (como a criação dos comitês de auditoria estatutários) e um acompanhamento maior dos auditores externos sob o modo como os gestores realizam suas escolhas contábeis (Gaganis et al., 2016). Isto fez com que as práticas de suavização por accruals fossem reduzidas ao longo do tempo e em troca houvesse um aumento das práticas de suavização por operações.

O resultado da suavização intencional de resultados por accruals não foi negativo para a comparabilidade, pelo contrário, para as empresas com os menores níveis de comparabilidade apresentou resultado positivo, possivelmente em decorrência do ganho de uniformidade gerado pelo lucro mais homogêneo. Este aspecto também foi observado por Tucker e Zarowin (2006), que relataram aumento da persistência nos lucros que foram mais suavizados. Contudo, este resultado precisa ser analisado com restrições, uma vez que a uniformidade não representa a comparabilidade genuína, como defendido por Ribeiro et al. (2016b). Segundo os autores, se a uniformidade for exacerbada, ela pode contribuir de modo negativo com a comparabilidade, pois a ideia da comparabilidade é identificar o que é igual, mas também o que é diferente. A uniformidade só identifica o que é igual. Este aspecto pode trazer um ganho para medida quando a comparabilidade é muito baixa, mesmo que traga uma perda quando ela já possui nível aceitável.

Este estudo não foi isento de limitações, pois assim como Ribeiro et al. (2016a) e Ribeiro et al. (2019), não foram consideradas possíveis políticas contábeis que afetam o resultado abrangente, além de o intervalo de pesquisa corresponder a um período de desaceleração da economia. Neste sentido, abre-se espaço para analisar o reflexo de outras práticas de manipulação de resultados na comparabilidade dos relatórios financeiros. Adicionalmente, sugere-se em pesquisas futuras a investigação dos reflexos externos, ambiente regulatório ou macroeconômico, nesta característica qualitativa de melhoria.

\section{REFERÊNCIAS}

Ahmed, Anwer S. and Neel, Michael J. and Safdar, Irfan. (2019). Accounting Comparability and the Market Pricing of Accruals. Advances in Accounting, 45. DOI: https://doi.org/10.1016/j.adiac.2019.03.003.

Almeida, J. E. F., Sarlo Neto, A., Bastianello, R. F., \& Moneque, E. Z. (2012). Alguns aspectos das práticas de suavização de resultados no conservadorismo das companhias abertas listadas na BM\&FBovespa. Revista Contabilidade \& Finanças, 23(58), 65-75. DOI: https://doi.org/10.1590/S1519-70772012000100005. 
Al-Taie, B. F. K., Flayyih, H. H., \& Talab, H. R. (2017). Measurement of Income Smoothing and Its Effect on Accounting Conservatism: An Empirical Study of Listed Companies in the Iraqi Stock Exchange. International Journal of Economic Perspectives, 11(3).

Bagnoli, M., \& Watts, S. G. (2010). Oligopoly, disclosure, and earnings management. The Accounting Review, 85(4), 1191-1214. DOI: https://doi.org/10.2308/accr.2010.85.4.1191.

Bao, B. H., \& Bao, D. H. (2004). Income smoothing, earnings quality and firm valuation. Journal of Business Finance \& Accounting, 31(9-10), 1525-1557.

Barth, M. E., Landsman, W. R., Lang, M., \& Williams, C. (2012). Are IFRS-based and US GAAP-based accounting amounts comparable? Journal of Accounting and Economics, 54(1), 68-93. DOI: https://doi.org/10.1016/j. jacceco.2012.03.001.

Beaver, W., Lambert, R., \& Morse, D. (1980). The information content of security prices. Journal of Accounting and Economics, 2(1), 3-28. DOI: https://doi.org/10.1016/0165-4101(80)90013-0.

Beaver, W. H., Lambert, R. A., \& Ryan, S. G. (1987). The information content of security prices: A second look. Journal of Accounting and Economics, 9(2), 139-157. DOI: https://doi.org/10.1016/0165-4101(87)90003-6.

Brochet, F., Jagolinzer, A. D., \& Riedl, E. J. (2013). Mandatory IFRS adoption and financial statement comparability. Contemporary Accounting Research, 30(4), 1373-1400. DOI: https://doi.org/10.1111/1911-3846.12002.

Brugni, T. V., Fávero, L. P. L., da Silva Flores, E., \& Beiruth, A. X. (2015). O vetor de causalidade entre lucro contábil e preço das ações: existem incentivos para a informação contábil seguir o preço no brasil?. Contabilidade Vista \& Revista, 26(1), 79-103.

Cascino, S., \& Gassen, J. (2012). Comparability effects of mandatory IFRS adoption. University of Humboldt, DOI: http://dx.doi.org/10.18452/4384.

Chen, A., \& Gong, J. J. (2019). Accounting comparability, financial reporting quality, and the pricing of accruals. Advances in accounting, 45, 100415. DOI: https://doi.org/10.1016/j.adiac.2019.03.003.

De Franco, G., Kothari, S. P., \& Verdi, R. S. (2011). The benefits of financial statement comparability. Journal of Accounting Research, 49(4), 895-931. DOI: https://doi.org/10.1111/j.1475-679X.2011.00415.x.

Dechow, P., Ge, W., \& Schrand, C. (2010). Understanding earnings quality: A review of the proxies, their determinants and their consequences. Journal of accounting and economics, 50(2-3), 344-401. DOI: https:// doi.org/10.1016/j.jacceco.2010.09.001.

DeFond, M., Hu, X., Hung, M., \& Li, S. (2011). The impact of mandatory IFRS adoption on foreign mutual fund ownership: The role of comparability. Journal of Accounting and Economics, 51(3), 240-258. DOI: https:// doi.org/10.1016/j.jacceco.2011.02.001.

Dopuch, N., \& Drake, D. F. (1966). The effect of alternative accounting rules for nonsubsidiary investments. Journal of Accounting Research, 192-219. DOI: https://doi.org/10.2307/2490182

Doyle, J. T., Ge, W., \& McVay, S. (2007). Accruals quality and internal control over financial reporting. The accounting review, 82(5), 1141-1170. DOI: https://doi.org/10.2308/accr.2007.82.5.1141.

Duarte, F. C. L., Girão, L. F. D. A. P., \& Paulo, E. (2017). Avaliando Modelos Lineares de Value Relevance: Eles Captam o que Deveriam Captar?. Revista de Administração Contemporânea, 21(spe), 110-134. DOI: https:// doi.org/10.1590/1982-7849rac2017160202.

Eckel, N. (1981). The income smoothing hypothesis revisited. Abacus, 17(1), 28-40. DOI: https://doi. org/10.1111/j.1467-6281.1981.tb00099.x.

Fang, V. W., Maffett, M., \& Zhang, B. (2015). Foreign institutional ownership and the global convergence of financial reporting practices. Journal of Accounting Research, 53(3), 593-631. DOI: https://doi.org/10.1111/1475679X.12076.

Fávero, L. P., \& Belfiore, P. (2017). Manual de análise de dados: estatística e modelagem multivariada com Excel ${ }^{\circledR}, S P S S \circledR$ e Stata ${ }^{\circledR}$. Elsevier Brasil.

Financial Accounting Standards Board - FASB. (2010). Conceptual Framework for Financial Reporting. Norwalk: Fasb. 
Francis, J., Hanna, J. D., \& Vincent, L. (1996). Causes and effects of discretionary asset write-offs. Journal of Accounting Research, 34, 117-134. DOI: https://doi.org/10.2307/2491429

Francis, J., LaFond, R., Olsson, P. M., \& Schipper, K. (2004). Costs of equity and earnings attributes. The accounting review, 79(4), 967-1010.

Gaganis, C., Hasan, I., \& Pasiouras, F. (2016). Regulations, institutions and income smoothing by managing technical reserves: International evidence from the insurance industry. Omega, 59, 113-129. DOI: https://doi. org/10.1016/j.omega.2015.05.010.

Gassen, J., Fülbier, R. U., \& Sellhorn, T. (2006). International differences in conditional conservatism-the role of unconditional conservatism and income smoothing. European Accounting Review, 15(4), 527-564. DOI: http://dx.doi.org/10.2139/ssrn.894254

Ge, W. (2009). Essays on real earnings management (Doctoral dissertation, McGill University).

Gordon, M. J. (1966). Discussion of The effect of alternative accounting rules for nonsubsidiary investments. Journal of Accounting Research, 220-223. DOI: http://dx.doi.org/10.2307/2490183.

Greene, W. H. (2000). Econometric analysis 4th edition. International edition, New Jersey: Prentice Hall, 201-215.

Healy, P. M. (1985). The effect of bonus schemes on accounting decisions. Journal of accounting and economics, 7(1-3), 85-107. DOI: https://doi.org/10.1016/0165-4101(85)90029-1.

Healy, P. M., \& Palepu, K. G. (2001). Information asymmetry, corporate disclosure, and the capital markets: A review of the empirical disclosure literature. Journal of accounting and economics, 31(1-3), 405-440. DOI: https://doi.org/10.1016/S0165-4101(01)00018-0.

Healy, P. M., \& Wahlen, J. M. (1999). A review of the earnings management literature and its implications for standard setting. Accounting horizons, 13(4), 365-383. DOI: https://doi.org/10.2308/acch.1999.13.4.365.

Jones, J. J. (1991). Earnings management during import relief investigations. Journal of accounting research, 193 228. DOI: https://doi.org/10.2307/2491047.

Kang, J. K. \& Stulz, R. M. (1997). Why is there a home bias? An analysis of foreign portfolio equity ownership in Japan. Journal of financial economics, 46(1), 3-28. DOI: https://doi.org/10.1016/S0304-405X(97)00023-8.

Kim, J. B., Li, L., Lu, L. Y., \& Yu, Y. (2016). Financial statement comparability and expected crash risk. Journal of Accounting and Economics, 61(2-3), 294-312. DOI: https://doi.org/10.1016/j.jacceco.2015.12.003.

Kolozsvari, A. C., \& da Silva Macedo, M. A. (2016). Análise da Influência da Presença da Suavização de Resultados sobre a Persistência dos Lucros no Mercado Brasileiro. Revista Contabilidade \& Finanças, 27(72), 306-319. DOI: https://doi.org/10.1590/1808-057x201602610.

Lang, M. H., Maffett, M. G., \& Owens, E. (2010). Earnings comovement and accounting comparability: The effects of mandatory IFRS adoption. Working paper, SSRN. DOI: http://dx.doi.org/10.2139/ssrn.1676937.

Lang, M., Lins, K. V., \& Maffett, M. (2012). Transparency, liquidity, and valuation: International evidence on when transparency matters most. Journal of Accounting Research, 50(3), 729-774. DOI: https://doi.org/10.1111/ j.1475-679X.2012.00442.x.

Lee, C. W. J., Li, L. Y., \& Yue, H. (2006). Performance, growth and earnings management. Review of Accounting Studies, 11(2-3), 305-334. DOI: https://doi.org/10.1007/s11142-006-9009-9.

Leuz, C., Nanda, D., \& Wysocki, P. D. (2003). Earnings management and investor protection: an international comparison. Journal of financial economics, 69(3), 505-527. DOI: https://doi.org/10.1016/S0304405X(03)00121-1.

McVay, S., Nagar, V., \& Tang, V. W. (2006). Trading incentives to meet the analyst forecast. Review of Accounting Studies, 11(4), 575-598. DOI: https://doi.org/10.1007/s11142-006-9017-9.

Myers, J. N., Myers, L. A., \& Skinner, D. J. (2007). Earnings momentum and earnings management. Journal of Accounting, Auditing \& Finance, 22(2), 249-284. DOI: https://doi.org/10.1177/0148558X0702200211.

Reina, D. R. M., de Carvalho, L. N. G., Reina, D., \& Lemes, S. (2019). Comparabilidade dos relatórios financeiros e informatividade dos preços das ações no Brasil. Revista Contemporânea de Contabilidade, 16(39), $177-$ 198. DOI: https://doi.org/10.5007/2175-8069.2019v16n39p177. 
Ribeiro, A. M. (2014). Poder discricionário do gestor e comparabilidade dos relatórios financeiros: uma análise dos efeitos da convergência do Brasil às IFRS (Doctoral dissertation, Universidade de São Paulo).

Ribeiro, A. M., do Carmo, C. H. S., Fávero, L. P. L., \& Carvalho, L. N. (2016a). Poder discricionário do gestor e comparabilidade dos relatórios financeiros: uma análise do processo de transição regulatória da contabilidade brasileira. Revista Contabilidade \& Finanças, 27(70), 12-28. DOI: https://doi.org/10.1590/1808$057 \times 201601900$.

Ribeiro, A. M., do Carmo, C. H. S., Fávero, L. P. L., \& de Carvalho, L. N. G. (2016b). Comparabilidade x uniformidade dos relatórios financeiros: uma análise empírica durante o período de transição regulatória da contabilidade brasileira ao padrão internacional. Advances in Scientific and Applied Accounting, 9(3), 262282. DOI: 10.14392/ASAA.2016090302

Ribeiro, A. M., de Sousa, A. M., \& Vicente, E. F. R. (2019) Impacto da Troca de Auditor na Comparabilidade dos Relatórios Financeiros: Uma Análise em Companhias Brasileiras de Capital Aberto. Anais do XIX USP International Conference in Accounting, São Paulo, Brasil, 1-20.

Ronen, J., \& Sadan, S. (1981). Smoothing income numbers: Objectives, means, and implications. Addison-Wesley Publishing Company.

Schipper, K., \& Vincent, L. (2003). Earnings quality. Accounting horizons, 17, 97-110.

Scott, W. R. (2015). Financial Accounting Theory 3rd ed. Upper Saddle River, NJ: Prentice Hall.

Simmons, J. K. (1967). A concept of comparability in financial reporting. The accounting review, 42(4), 680-692.

Skinner, D., \& Myers, L. (1999). Earnings momentum and earnings management. Unpublished working paper, University of Michigan and University of Illinois.

Sohn, B. C. (2016). The effect of accounting comparability on the accrual-based and real earnings management. Journal of Accounting and Public Policy, 35(5), 513-539. DOI: https://doi.org/10.1016/j. jaccpubpol.2016.06.003.

Talebnia, H. V. G., \& Javanmard, S. A. (2011). The interaction of income smoothing and conditional accounting conservatism: Empirical evidence from Iran. African Journal of Business Management, 5(34), 13302-13308. DOI: https://doi.org/10.5897/AJBM11.1706.

Tucker, J. W., \& Zarowin, P. A. (2006). Does income smoothing improve earnings informativeness?. The accounting review, 81(1), 251-270.

Verrecchia, R. E., \& Weber, J. (2006). Redacted disclosure. Journal of Accounting Research, 44(4), 791-814. DOI: https://doi.org/10.1111/j.1475-679X.2006.00216.x.

Watts, R. L., \& Zimmerman, J. L. (1986). Positive accounting theory. Prentice Hall International Editions.

Yang, Z., Su, R., Zhou, S., \& Li, Y. (2016). Earnings Management, Annual Report and Accounting Comparability. International journal of Business and Management, 11(10), 51-68. DOI: https://doi.org/10.5539/ijbm. v11n10p51.

Yip, R. W., \& Young, D. (2012). Does mandatory IFRS adoption improve information comparability?. The Accounting Review, 87(5), 1767-1789.

Zang, A. Y. (2012). Evidence on the trade-off between real activities manipulation and accrual-based earnings management. The accounting review, 87(2), 675-703.

\section{Como citar este artigo}

Sousa, A. M. de, Ribeiro, A. M., Vicente, E. F. R., \& Carmo, C. H. S. do. (2020). Suavização de resultados e comparabilidade dos relatórios financeiros: evidências em empresas abertas do mercado brasileiro. Revista de Contabilidade e Organizações, 14:e164488. DOI: http://dx.doi.org/10.11606/issn.1982-6486. rco.2020.164488 


\section{Apêndice A}

As medidas de suavização intencional utilizadas nesta pesquisa constam no trabalho de Lang et al. (2012). Os autores apresentam duas formas para medir aspectos esta forma de manipulação dos resultados, denominados de Smoothing 1 (SMTH1) e Smoothing 2 (SMTH2).

Lang et al. (2012) destacam que o SMTH1 capta a volatilidade dos lucros em relação ao fluxo de caixa operacional no período. Leuz et al. (2003) e Francis, LaFond, Olsson e Schipper (2004), argumentam, que quanto mais as empresas utilizam os accruals para fins de gerenciamento de resultados o lucro será mais suavizado em comparação aos fluxos de caixa final do exercício. Desse modo, o SMTH1 capta a suavização de resultados ligada aos accruals, bem como, as questões operacionais da empresa. Com isso, pode-se entender que esta medida capta um aspecto da suavização de resultados mais geral.

Em relação à forma desta medida, Lang et al (2012) descrevem que o SMTH1 consiste nos desviospadrão do lucro líquido antes dos itens extraordinários final do período com os desvios-padrão dos fluxos de caixa operacionais do final de cada período, ao utilizar o intervalo dos últimos três a cinco períodos anuais. Contudo, no que concerne ao SMTH1, realizou-se uma adaptação ao utilizar o lucro líquido do final do período ao invés do lucro líquido antes dos itens extraordinários.

Nesse contexto, utilizou-se o intervalo de três períodos anuais, ou seja, doze trimestres que compreende ao trimestre atual mais os onze trimestres anteriores. Em momento posterior ao cálculo do SMTH1 e, seguindo os procedimentos realizados por Lang et al. (2012), realizou-se a multiplicação do SMTH1 por -1. Esta multiplicação foi necessária para que os maiores valores da variável SMTH1 correspondam aos maiores níveis de suavização e, do mesmo modo, os menores resultados compreendam aos menores níveis suavizações. Assim, torna a medida mais intuitiva ao demonstrar que quanto maior o valor da medida (SMTH1) maior é o nível de suavização de resultados. Dado as informações acerca do desenho da métrica, o SMTH1 foi calculado por meio da Equação 1:

$$
S M T H 1=(\sigma L L / \sigma F C O) *-1
$$

Onde: SMTH1 = suavização geral de resultados; $\sigma \mathrm{LL}$ = desvio-padrão do lucro líquido do fim do período de 12 trimestres, e; $\sigma \mathrm{FCO}=$ desvio-padrão do fluxo de caixa operacional do fim do período de 12 trimestres.

O SMTH2 é calculado a partir da correlação entre a fluxo de caixa operacional do final do período dividido pelos ativos totais com os accruals totais do final do período dividido pelos ativos totais do final do período. Lang et al. (2012) comentam que quando o teste de correlação destas duas variáveis resultar em um coeficiente negativo, indica que há maior nível de suavização de resultados por accruals. Em que esta ideia central desta medida, está pautada em capturar o aumento do uso de accruals discricionários em períodos com diminuição dos lucros. Caso este movimento persista ao longo do tempo, o coeficiente de correlação do teste será negativo. Dessa forma, de acordo com a lógica da equação descrita por Lang et al. (2012), Leuz et al. (2003) e Francis et al. (2004), é um indicativo que a empresa apresenta lucro suavizado por meio accruals.

O SMTH2 foi calculado a partir da correlação entre a fluxo de caixa operacional do final do período dividido pelos ativos totais em relação aos accruals totais do final do período dividido pelos ativos totais do final do período do trimestre atual e dos últimos onze trimestres anteriores. Ressalta-se que a variável SMTH2 também foi multiplicada por -1, conforme o procedimento realizado por Lang et al. (2012). Multiplicação necessária para que a segunda medida (SMTH2) também se tornasse mais intuitiva quanto a sua interpretação, pois com esta multiplicação, quanto maior o resultado desta medida, maior a suavização de resultados por accruals.

$$
\text { SMTH2 }=\rho[(F C O / A T),(\text { Accruals } / A T)]^{*}-1
$$

Em que: SMTH2 = suavização intencional de resultados por accruals; FCO = fluxo de caixa operacional do fim do período de 12 trimestres; AT = ativo total do fim do período de 12 trimestres, e; Accruals = accruals totais do fim do período de 12 trimestres.

Com as medidas que captam a suavização geral de resultados e a suavização de resultados por accruals (SMTH1 e SMTH2, respectivamente) calculadas. O próximo passo consistiu em submeter estas medidas à Equação 3. A partir desta equação, pôde-se separar a suavização intencional geral de resultados (SUAV1) da suavização natural geral de resultados, em que estas duas somadas compreendem a suavização total geral de resultados (SMTH1). 
Da mesma forma, com a Equação 3, pôde-se discriminar a suavização intencional de resultados por accruals (SUAV2) da suavização natural de resultados por accruals, isto é, decorrente das atividades operacionais da empresa. Sendo que estes dois tipos de suavização por accruals (natural e intencional) compõe a suavização de resultados por accruals total (SMTH2). Assim, procedeu-se ao cálculo da SUAV1 e SUAV2, que correspondem ao termo de erro dos seguintes modelos multivariados com a SMTH1 e SMTH2, respectivamente, como as variáveis dependentes, conforme consta no trabalho de Lang et al. (2012):

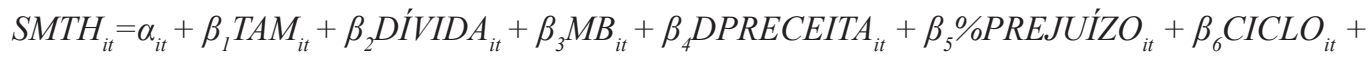

$$
\begin{aligned}
& \beta_{7} \text { CRESCREC }_{i t}+\beta_{8} I M O B_{i t}+\beta_{9} F L U X O_{i t}+\beta_{10} A N O_{i t}+\beta_{11} S E T O R_{i t}+\varepsilon_{i t}
\end{aligned}
$$

Em que: $\mathrm{TAM}_{\mathrm{it}}=$ logaritmo do ativo total do final do exercício da empresa i no período t; DÍVIDA ${ }_{\mathrm{it}}=$ dívida total (empréstimos e financiamentos de curto e longo prazo) do final do exercício dividido pelo ativo total do final do exercício da empresa i no período $\mathrm{t} ; \mathrm{MB}_{\mathrm{it}}=$ market-to-book do final do exercício da empresa i no período t; DPRECEITA it $_{\text {i }}=$ desvio-padrão da receitas líquida do exercício dos últimos doze trimestres (3 anos) da empresa i no período t; \% $\%$ PREJÍZO $\mathrm{it}_{\mathrm{it}}=$ proporção dos períodos que houve resultado líquido negativo dos últimos doze trimestres ( 3 anos) da empresa i no período t; $\mathrm{CICLO}_{\mathrm{it}}=$ logaritmo do Ciclo Operacional (ciclo operacional $=$ prazo médio de estocagem + prazo médio de recebimento) final do exercício da empresa i no período

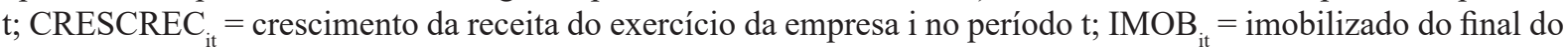
exercício dividido pelo ativo total do final do exercício da empresa i no período $t$; $\mathrm{FLUXO}_{\mathrm{it}}=$ fluxo de caixa médio operacional dividido pelo ativo total do final do exercício da empresa i no período $\mathrm{t}$; $\mathrm{ANO}_{\mathrm{it}}=$ períodos anuais, de 2012 a 2017, e; SETOR $_{\mathrm{it}}=$ representa o setor de atividade econômica da companhia da empresa i no período t.

Em momento posterior à determinação da SUAV1 e SUAV2, Lang et al. (2012) realizou a multiplicação destas variáveis a qual é denominada de DIS_SMTHC que corresponde à manipulação de resultados decorrente de práticas intencionais de suavização de resultados. Entretanto, na presente pesquisa, optou-se por não realizar este procedimento de multiplicação da SUAV1 e SUAV2. Porque, ao considerar o resultado do teste de correlação de Pearson, verifica-se que este teste apresentou coeficiente de correlação de -0,0236.

Nesse sentido, estas duas variáveis, apesar de estarem serem similares, não apresentam o mesmo comportamento no mesmo período. Uma justificativa para isso está ligada à forma de suavização utilizada pelos gestores de acordo com o período. Porque a depender do resultado do exercício, o gestor poderá optar pela suavização de resultados a partir de aspectos gerais, que tangem até mesmo as operações da empresa, ou fazer apenas o uso de accruals para suavizar os resultados no período. Estas duas formas de manipulação de resultados são distintas e, segundo Zhang (2012), se complementam, mas são utilizadas pelos gestores em momentos distintos conforme o propósito dos gestores. A partir disso, optou-se, diferente de Lang et al. (2012), por analisar o impacto das duas medidas de suavização de resultados separadamente e não em uma única variável.

Após a determinação da SUAV1 e SUAV2, os valores correspondentes a estas variáveis - que compreendem ao resíduo da estimação da SMTH1 e SMTH2 da Equação 3 - foram transformados a partir dos seus respectivos valores em módulo. Esta transformação foi necessária, pois quanto maior a distância do termo de erro em relação à reta da regressão, maior é o nível de suavização intencional geral de resultados e suavização intencional de resultados por accruals. Assim, para medir adequadamente a SUAV1 e SUAV2, foi necessário que as observações referentes a estas variáveis fossem transformadas em módulo. Desse modo, todas as observações destas variáveis com valores negativos se tornaram positivos e as observações destas variáveis que apresentavam valores positivos continuaram com o mesmo valor. Portanto, quanto maior o valor da SUAV1 ou SUAV2, maior é a suavização intencional geral de resultados e suavização intencional de resultados por accruals, respectivamente.

\section{Apêndice B}

A medida de comparabilidade consiste na desenvolvida por DeFranco et al. (2011), isto é, a similaridade da função contábil. Para tanto, inicialmente foi estimada a função contábil de cada companhia ao considerar os últimos 12 períodos trimestrais, conforme as adaptações que constam no trabalho de Yip e Young (2012) ao substituir o valor de mercado pelo ativo total. Esta adaptação, segundo os autores, também mantém as propriedades do trabalho original ao captar os reflexos dos eventos econômicos nos relatórios financeiros. Além disso, esta adaptação também foi utilizada em outros trabalhos, como o de Ribeiro et al. (2016a) e Ribeiro et al. (2016b). Com isso, a função de cada companhia foi estimada conforme a seguinte equação:

$$
R O A_{i t}=\alpha_{i}+\beta_{i} \text { Retorno }_{i t}+\varepsilon_{i t}
$$


Onde: $\mathrm{ROA}_{\mathrm{it}}=$ lucro líquido trimestral do exercício sobre o ativo total do final do exercício companhia i no período t não consolidado, e Retorno ${ }_{i t}=$ retorno acionário final do exercício trimestral da companhia i no período t, calculado a partir do preço de fechamento das ações ordinárias, ajustado para proventos e desdobramentos. Em momento posterior, estimou-se os parâmetros das funções contábeis individuais ao projetar o ROA esperado [E(ROA)] das companhias, individualmente, com base nos resultados da Equação 4. Desse modo, tem-se a equação para o cálculo do $[\mathrm{E}(\mathrm{ROA})]$.

$$
E(R O A)_{i i t}=\widehat{\alpha}_{i}+\widehat{\beta}_{i} \text { Retorno }_{i t}
$$

Onde: $\mathrm{E}(\mathrm{ROA})_{\mathrm{iit}}=\mathrm{ROA}$ esperado da empresa i com os parâmetros da companhia i no período $\mathrm{t}$, e Retorno $_{\text {it }}=$ retorno acionário final do exercício trimestral da companhia i no período t, calculado a partir do preço de fechamento das ações ordinárias, ajustado para proventos e desdobramentos. O próximo passo consistiu em calcular o ROA esperado da mesma empresa com os estimadores das demais companhias que são do mesmo setor, por meio da seguinte equação.

$$
E(R O A)_{i j t}=\widehat{\alpha}_{i}+\widehat{\beta}_{i} \text { Retorno }_{i t}
$$

Onde: $\mathrm{E}(\mathrm{ROA})_{\mathrm{iji}}=\mathrm{ROA}$ esperado da empresa i com os parâmetros da companhia j no período t, e Retorno ${ }_{\mathrm{it}}$ = retorno acionário final do exercício trimestral da companhia i no período $t$, calculado a partir do preço de fechamento das ações ordinárias, ajustado para proventos e desdobramentos.

No momento em que se considera o evento econômico de uma empresa com os estimadores das demais companhias do mesmo setor, tem-se como ideia que o evento econômico constante se mantenha. A medida de comparabilidade das empresas consiste na média da distância dos resultados obtidos a partir dos resultados da Equação 5 e 6, ao considerar o intervalo de período trimestral, ou seja, $\left[\mathrm{E}\left(\mathrm{ROA}_{\mathrm{iit}}\right)-\mathrm{E}\left(\mathrm{ROA}_{\mathrm{ijt}}\right)\right]$. DeFranco et al. (2011), discorrem que quanto mais próximos os valores resultantes dessas duas funções, maior é a comparabilidade entre as companhias. Com a finalidade de medir a comparabilidade das companhias, ao considerar os seus pares, calculou-se a média da distância de cada função contábil, no que confere o intervalo do período trimestral a partir da seguinte equação:

$$
\operatorname{Comp}_{i j t}=-\frac{1}{12} \sum_{t-11}^{t}\left|E\left(R O A_{i i t}\right)-E\left(R O A_{i j t}\right)\right|
$$

Em que: $\mathrm{Compb}_{\mathrm{ijt}}=$ medida de comparabilidade individual relativa da companhia i com base na empresa j no período t; $E(R O A)_{i i t}=R O A$ esperado da empresa i com os parâmetros da companhia i no período $t$, e $\mathrm{E}(\mathrm{ROA})_{\mathrm{iji}}=\mathrm{ROA}$ esperado da empresa i com os parâmetros da companhia $\mathrm{j}$ no período $\mathrm{t}$.

Os resultados da Equação 7 correspondem às distancias médias das funções contábeis de duas empresas pertencentes ao mesmo setor. Desta maneira, ao calcular a média dos valores resultantes da Equação 7 referente à comparabilidade dos pares de empresas, tem-se a média de comparabilidade média de cada empresa, em que essa é calculada a partir da seguinte equação:

$$
\operatorname{COMPM}_{i t}=\frac{\operatorname{Compb}_{i j t}}{n}
$$

Onde: $\mathrm{COMPM}_{\mathrm{it}}=$ medida de comparabilidade de cada empresa em relação aos seus pares que pertencem ao mesmo setor; $\mathrm{Compb}_{\mathrm{ijt}}=$ medida de comparabilidade individual relativa da companhia $\mathrm{i}$ com base na empresa $\mathrm{j}$ no período $\mathrm{t}, \mathrm{e} ; \mathrm{n}=$ número de companhias do setor

Como expressado acima, foram realizadas adaptações do modelo original de DeFranco, et al. (2011). Essas adaptações se referem ao intervalo de período, em que foi utilizado 12 períodos trimestrais ao invés de 16 períodos trimestrais como no trabalho original. Estudos similares realizaram adaptações do modelo original, tais como Yip; Young (2012), Cascino e Gassen (2012), Brochet, et al. (2013), e por fim, Ribeiro et al. (2016a) e Ribeiro et al. (2016b). 